\title{
Can the Safety Net be Age-Friendly? How to Address Its Important Role in Caring for Older Adults with Geriatric Conditions
}

\author{
Anna Haseltine Chodos, MD, MPH ${ }^{1,2}{ }^{\circ}$, Christine Karen Cassel, $\mathrm{MD}^{1}$, and \\ Christine Seel Ritchie, MD, MSPH ${ }^{3}$
}

'Division of Geriatric, Department of Medicine, University of California, San Francisco, CA, USA; ${ }^{2}$ Division of General Internal Medicine at Zuckerberg San Francisco General Hospital, Department of Medicine, University of California, San Francisco, CA, USA; ${ }^{3}$ Mongan Institute and the Division of Palliative Care and Geriatric Medicine, Massachusetts General Hospital, Boston, MA, USA.

\begin{abstract}
The safety net, a collection of public hospitals, federally qualified health centers (FQHCs), and publicly funded community-based healthcare entities, provides essential care to middle-aged and older adults with geriatric conditions. The role of the safety net for these adults will intensify over the next two decades with the growing numbers of middle-aged and older adults with adverse social determinants of health and premature geriatric conditions. The foundation for addressing their needs is to detect geriatric conditions and then focus care plans on the impact of these factors on function, which predicts mortality and quality of life more than chronic conditions alone. To detect geriatric conditions in safety net populations, the Age-Friendly Health System (AFHS) framework offers an evidence-based focus on the 4Ms: Mentation, Mobility, Medications, and what Matters. Further incorporating geriatric care models that target the $4 \mathrm{Ms}$ and are adapted to safety net populations will enable age-friendly care that optimizes health and addresses what matters to older people.
\end{abstract}

J Gen Intern Med 35(11):3338-41

DOI: $10.1007 / \mathrm{s} 11606-020-06010-\mathrm{x}$

(C) Society of General Internal Medicine 2020

$\mathrm{T}$ he safety net, a collection of public hospitals, federally qualified health centers (FQHCs), and publicly funded community-based healthcare entities, is an essential component of our health system for low-income and uninsured people. It is often thought to be the place for marginalized and vulnerable populations, the working poor, children, and women of reproductive age. Most people do not realize that the safety net also provides essential care to older adults (typically defined as 65 and older) and those that may be younger but experiencing geriatric conditions, like dementia or frailty.

Received November 19, 2019

Accepted June 23, 2020

Published online July 6, 2020
The role of the safety net for geriatric care will intensify over the next two decades as older adults begin to outnumber children in our society. While older adults or certain adults with disabilities can get Medicare insurance, that does not translate into them leaving the safety net. They may be more comfortable with healthcare there because of accessibility, language and cultural concordance, or coordination with other desired services, such as substance use treatment or supportive housing. For many, Medicare's growing premiums and deductibles leave high out-of-pocket expenditures to patients that are difficult to cover outside of the safety net. ${ }^{1}$ There are an increasing number of studies that those in later middle-age (45-64 years old) who have experienced adverse social determinants of health prematurely develop chronic illness and therefore experience geriatric conditions at earlier chronological ages; and these are the adults more likely to be seen in a safety net setting. We explain this more below and how the needs of these patients can be met with high-quality geriatric care.

\section{THE SAFETY NET WILL SERVE MORE PATIENTS WITH GERIATRIC CONDITIONS}

The safety net can expect to see more older adults because of the increasingly diverse racial and ethnic diversity of older adults along with economic disparities often seen in these minority populations. ${ }^{2}$ These characteristics increase the likelihood that these older adults will seek care in the safety net, e.g., because of limited English proficiency, an array of cultural backgrounds, gender identity, sexual orientation, race, and ethnicity. ${ }^{3-6}$ Older adults are the only demographic for whom the poverty rate is increasing, a factor contributing to the growing number of older adults experiencing homelessness, often for the first time in their lives. ${ }^{7,8}$ Even with Medicare insurance, adults seek care in the safety net. From 2006 to 2010 , almost $20 \%$ of visits in safety net primary care nationally were by Medicare-insured adults. ${ }^{9}$ These adults were more likely to be Black or Hispanic, have multimorbidity, experience polypharmacy, and be from neighborhoods with high rates of poverty than those who go to nonsafety net sites; almost a third of safety net patients were dually eligible for Medicare and Medicaid. ${ }^{9}$ 
In addition to the growth of older adults in safety net settings, it is important to note that geriatric syndromes do not only affect those 65 and older. Those adults with adverse social determinants of health or chronic illness in their 50s and older demonstrate a higher prevalence of geriatric conditions such as functional impairment, urinary incontinence, frailty, falls, and dementia than the general population (see Table 1). ${ }^{10-15}$ For example, the population of people living with HIV (PLWH) is growing older, such that in San Francisco two-thirds of PLWH are now 50 and older, the ages at which geriatric syndromes are more prevalent in this population. ${ }^{16}$ The aging trend also affects jails and prisons, where the population is aging at a faster rate than the nation and has geriatric syndromes, such as frailty and cognitive impairment, starting in middle age. ${ }^{13,17}$ Incarcerated persons along with those living with HIV are often served by safety net healthcare programs, such as public hospitals and federally funded programs. ${ }^{18,} 19$

\section{WHAT SAFETY NET INSTITUTIONS CAN DO TO PREPARE FOR ADULTS WITH GERIATRIC CONDITIONS}

The keys to preparation on a systems level will be to identify which patients to target for geriatric care, and leverage workforce training and care transformation opportunities that directly improve the care for those with geriatric conditions. Transformation may occur through an improved focus on geriatrics within existing programs or by implementing an array of complementary geriatrics programs, many of which have proven track records in the safety net.

Table 1 Geriatric Conditions in Adults 50 and Older with High Burden of Social Determinants of Health

\begin{tabular}{|c|c|c|}
\hline Population & $\begin{array}{l}\text { Increased prevalence } \\
\text { of geriatric } \\
\text { conditions }\end{array}$ & $\begin{array}{l}\text { Sample } \\
\text { characteristics and } \\
\text { comparison group }\end{array}$ \\
\hline $\begin{array}{l}\text { Older adults } \\
\text { chronically } \\
\text { experiencing } \\
\text { homelessness }\end{array}$ & $\begin{array}{l}\text { Frailty } \\
\text { Functional Impairment } \\
\text { Mobility impairment } \\
\text { Cognitive impairment } \\
\text { Depression } \\
\text { Visual impairment } \\
\text { Hearing impairment } \\
\text { Urinary incontinence }\end{array}$ & $\begin{array}{l}\text { Population-based } \\
\text { sample, comparison to } \\
\text { general population. } \\
\text { Adults age } 50 \text { and } \\
\text { older. }\end{array}$ \\
\hline $\begin{array}{l}\text { Older adults who } \\
\text { are incarcerated }\end{array}$ & $\begin{array}{l}\text { Falls } \\
\text { Incontinence } \\
\text { Functional Impairment } \\
\text { Mobility impairment } \\
\text { Hearing impairment } \\
\text { Multimorbidity }\end{array}$ & $\begin{array}{l}\text { Compared with } \\
\text { community-dwelling } \\
\text { and low socioeconomic } \\
\text { status older adults. } \\
\text { Adults } 55 \text { and older. }\end{array}$ \\
\hline $\begin{array}{l}\text { Older adults living } \\
\text { with HIV } \\
\text { (Greene) }\end{array}$ & $\begin{array}{l}\text { Pre-frailty } \\
\text { Falls } \\
\text { Incontinence } \\
\text { Functional Impairment } \\
\text { Mobility impairment } \\
\text { Hearing impairment } \\
\text { Visual impairment } \\
\text { Cognitive impairment } \\
\text { Depression }\end{array}$ & $\begin{array}{l}\text { Risk factors for } \\
\text { geriatric syndromes } \\
\text { included HIV-related } \\
\text { and non-HIV-related } \\
\text { factors. }\end{array}$ \\
\hline $\begin{array}{l}\text { Hospitalized older } \\
\text { adults in a safety } \\
\text { net hospital }\end{array}$ & $\begin{array}{l}\text { Hospitalization- } \\
\text { associated disability } \\
\text { (i.e., ADLs disability } \\
\text { associated with a } \\
\text { hospitalization) }\end{array}$ & Adults 55 and older. \\
\hline
\end{tabular}

First, to target the right patients, safety net institutions must query about functional status and geriatric conditions in middle-aged and older patients based on their higher prevalence of risk factors for them. Geriatric conditions and functional status are more predictive of mortality than diagnoses of chronic diseases alone. ${ }^{20,21}$ Once they are identified, care plans can focus on addressing them and minimizing the impact of these conditions on the person's well-being. For example, a brief geriatric screen and response plan could include functional status ascertainment that would lead to a referral to caregiver services; self-reported concerns about thinking or memory that would lead to cognitive assessment; fall risk assessment that would lead to a home safety evaluation; and sensory impairment screening that would lead to a referral to hearing or vision assessments and resources.

Second, we must geriatricize our safety net systems broadly despite a national shortage of geriatrics-trained professionals. An opportunity is to partner with one of the federally funded Geriatrics Workforce Enhancement Programs (GWEPs), which were established in 2015 and are currently in 37 states and US territories. ${ }^{22}$ They bring geriatrics training to front-line primary care providers and community social service providers. Training occurs via in-person trainings and increasingly through remote education, e.g., via teleconferencing. GWEP initiatives have also supported clinical care transformation, for example, through the implementation of Annual Wellness Visits at FQHCs, falls screening programs in primary care, and partnerships with clinic-based pharmacists to stop high-risk medications.

Safety net institutions can also geriatricize existing inpatient and outpatient programs by joining the recent and growing movement toward Age-Friendly Health Systems (AFHS). This initiative, developed by the John A Hartford Foundation and the Institute for Healthcare Improvement (IHI), offers an evidence-based framework of four areas, called "the 4Ms," that lead to better care and outcomes for older people: Mentation, Mobility, Medications, and what Matters. The guide to using the $4 \mathrm{Ms}$ is available on-line. ${ }^{23}$

Participation in the AFHS requires a commitment to measure and improve care for older adults. It begins with an internal needs assessment, joining an action community to test interventions aimed at improving care quality for older adults, and demonstrating leadership commitment and champions. Implementation of the framework, which includes demonstrating the ability to measure quality of care, brings formal recognition by the IHI as an AgeFriendly Health System. Within clinical settings, decision support tools can optimize standardized geriatrics assessment and ascertainment of key geriatric conditions to begin to get baseline data. The IHI has resources for a return on investment calculation and for implementation of the 4Ms within an electronic medical record to leverage IT to measure important geriatric domains such as functional status that can identify adults at risk for geriatric conditions and guide intervention. ${ }^{24}$ 
Third, adopting geriatrics clinical models with proven impact on the health of older adults across care settings provides another way forward. Models that have improved outcomes for low-income adults in safety net settings include the inpatient Acute Care for Elders units (team-based inpatient care to reduce hospital-associated outcomes), outpatient Geriatrics Resources for the Assessment and Care of Elders (GRACE; interprofessional geriatrics co-management in primary care), the Aging-Brain Care program for adults with dementia and depression in the community through trained community health workers, and Programs of All-Inclusive Care of the Elderly (PACE) ${ }^{25-28}$ For dual-eligible adults who have functional impairment and live in the community, PACE (available in 31 states) integrates a person's care from outpatient to longterm care through capitated reimbursement and prevents nursing home admission. An innovative-adapted PACE model is St. Paul's PACE in San Diego which was created specifically for older adults experiencing homelessness to meet their housing, medical, and functional care needs in one program. ${ }^{29}$

Success of these programs for patients with geriatric conditions involves not just health systems transformation but also working with community partners that provide services to meet their functional and social needs and support their caregivers, the bedrock of their health and stability. This is well-suited to safety net systems, which often collaborate with community services that serve vulnerable or underserved populations already.

Community-services collaboration in a healthcare setting could include activities that are inherent to programs like GRACE, which invites community service agencies to attend weekly interprofessional team meetings to discuss patients' needs and move forward on connecting them to services. Or targeted processes of referral to these agencies could be developed, such as In-Home Supportive Services (IHSS) for functional needs at home; transportation agencies; home healthcare agencies that provide skilled services; community-based organizations, such as caregiver support organizations; and legal services that specialize in elder law. One consideration would be to cultivate a strong relationship with the local Area Agency on Aging, often a hub for services (e.g., Adult Protective Services, In Home Supportive-Services) for underserved older adults and adults with disabilities.

Fourth, further efforts should expand geriatrics programs and services to be uniquely relevant to the safety net and the aging populations they serve. These include services specializing in older adults at risk of or experiencing homelessness, substance use disorder treatment, transitions from incarcerated settings, and HIV care. Examples are the Golden Compass Clinic at Zuckerberg San Francisco General, a program embedded in an HIV primary care clinic with a consultative focus on those adults 50 and older. ${ }^{30}$ They screen for a broad number of geriatric conditions and then provide team-based assistance and recommendations, e.g., a pharmacist assists with complex polypharmacy, and the patient is connected to resources specific for their HIV disease and older age.
Finally, the local patient population may influence the development of these programs. For example, in San Francisco, Asian older adults comprise a large proportion of older adults living in the city and are the largest group of low-income older adults. They are more likely to be foreign-born and have limited English proficiency than other older adults. An important consideration is that this population requires language and culturally concordant approaches to geriatric care, such as in addressing advance care planning. ${ }^{31}$

\section{CONCLUSION}

The demographic transformation before us and the needs of low-income, marginalized, and underserved populations demand that we adequately prepare the safety net healthcare system to serve adults with geriatric conditions. Without a specialized workforce, all team members must be prepared to meet their needs with highquality care. A number of strategies can guide safety net institutions to provide better geriatrics care. These strategies include better assessment and identification of those with geriatric conditions and integration of effective geriatrics care models into safety net systems. The time is now to adopt these strategies and optimize care for those with geriatric care needs.

Corresponding Author: Anna Haseltine Chodos, MD, MPH; Division of General Internal Medicine at Zuckerberg San Francisco General Hospital, Department of Medicine, University of California, San Francisco, CA, USA (e-mail: anna.chodos@ucsf.edu).

\section{Compliance with Ethical Standards:}

Conflict of Interest: The authors declare that they do not have a conflict of interest.

\section{REFERENCES}

1. Norris L. How did Medicare benefits change for 2020? https://www. medicareresources.org/faqs/what-kind-of-medicare-benefit-changescan-i-expect-this-year/. Published 2020.

2. 2018 Profile of Older Americans. Administration for Community Living; April 20182018.

3. Lewin ME, Baxter RJ. America's health care safety net: revisiting the 2000 IOM report. Health Aff (Millwood). 2007;26(5): 1490-1494.

4. Medicine Io. America's Health Care Safety Net: Intact but Endangered. Washington 2000 .

5. Shi L, Lebrun LA, Tsai J, Zhu J. Characteristics of ambulatory care patients and services: a comparison of community health centers and physicians' offices. J Health Care Poor Underserved. 2010;21(4):11691183.

6. Choi SK, Meyer IH. LGBT Aging: A Review of Research Findings, Needs, and Policy Implications. . Los Angeles: The Williams Institute;2016.

7. Edwards A, Bee A, Fox L. Outlying Older Americans: The Puzzle of Increasing Poverty among those 65 and Older. https://www.census.gov/ newsroom/blogs/random-samplings/2017/09/outlying_older_ameri. html. Published 2017.

8. Culhane D, Treglia D, Byrne T, et al. The Emerging Crisis of Aged Homelessness: Could Housing Solutions Be Funded by Avoidance of Excess Shelter, Hospital, and Nursing Home Costs?: Actionable Intelligence for Social Policy;2019. 
9. Nguyen OK, Makam AN, Halm EA. National use of safety-net clinics for primary care among adults with non-Medicaid insurance in the United States. PLoS One. 2016;11(3): 0151610

10. Brown RT, Kiely DK, Bharel M, Mitchell SL. Geriatric syndromes in older homeless adults. Journal of general internal medicine. 2012;27(1):16-22

11. Henwood BF, Lahey J, Rhoades H, Pitts DB, Pynoos J, Brown RT. Geriatric conditions among formerly homeless older adults living in permanent supportive housing. Journal of general internal medicine. 2019;34(6):802-803.

12. Brown RT, Hemati $\mathbf{K}$, Riley ED, et al. Geriatric conditions in a population-based sample of older homeless adults. The Gerontologist. 2017;57(4):757-766.

13. Greene M, Ahalt C, Stijacic-Cenzer I, Metzger L, Williams B. Older adults in jail: high rates and early onset of geriatric conditions. Health Justice. 2018;6(1):3.

14. Chodos AH, Kushel MB, Greysen SR, et al. Hospitalization-associated disability in adults admitted to a safety-net hospital. Journal of general internal medicine. 2015;30(12):1765-1772.

15. Greene M, Covinsky KE, Valcour V, et al. Geriatric syndromes in older HIV-infected adults. J Acquir Immune Defic Syndr. 2015;69(2):161-167.

16. HIV Epidemiology Annual Report 2017. HIV Epidemiology Section, San Francisco Department of Public Health;2017.

17. Williams BA, Goodwin JS, Baillargeon J, Ahalt C, Walter LC. Addressing the aging crisis in U.S. criminal justice health care. Journal of the American Geriatric Society. 2012;60(6):1150-1156.

18. Haber LA, Erickson HP, Ranji SR, Ortiz GM, Pratt LA. Acute care for patients who are incarcerated: a review. JAMA Intern Med. 2019

19. The Ryan White HIV/AIDS Program: The Basics. Kaiser Family Foundation February 20192019

20. Komisar HL, Feder J. Transforming care for Medicare beneficiaries with chronic conditions and long-term care needs: coordinating care across all services. National Health Policy Forum: George Washington University; October 20112011.

21. Middleton A, Fritz SL, Lusardi M. Walking speed: the functional vital sign. J Aging Phys Act. 2015;23(2):314-322.
22. GWEP Coordinating Center. https://www.americangeriatric.org/programs/gwep-coordinating-center. Accessed.

23. Age-Friendly Health Systems: Guide to Using the $4 \mathrm{Ms}$ in the Care of Older Adults. Institute for Health Care Improvement. http://www.ihi.org/ Engage/Initiatives /Age-Friendly-Health-Systems / Documents / IHIAgeFriendlyHealthSystems_GuidetoUsing4MsCare.pdf. Published 2019. Accessed March 10, 2020.

24. Resources to Practice Age-Friendly Care. Institute for Healthcare Improvement. http://www.ihi.org/Engage/Initiatives/Age-Friendly-HealthSystems/Pages/Resources.aspx. Accessed March 10, 2020.

25. Alder CA, LaMantia MA, Austrom MG, Boustani MA. The Indiana Aging Brain Care Project. In: Malone ML, Capezuti EA, Palmer RM, eds. Geriatric Models of Care: Bringing 'Best Practice' to an Aging America. Cham: Springer International Publishing; 2015:231-237.

26. Counsell SR, Callahan CM, Buttar AB, Clark DO, Frank KI. Geriatric Resources for Assessment and Care of Elders (GRACE): a new model of primary care for low-income seniors. J Am Geriatr Soc. 2006;54(7):11361141.

27. Gonzalez L. A Focus on the Program of All-Inclusive Care for the Elderly (PACE). J Aging Soc Policy. 2017;29(5):475-490.

28. Palmer RM. The acute care for elders unit model of care. Geriatric (Basel). 2018;3(3).

29. Priestley DA, McBride MB, Leopold C. Tocopherol and organic free radical levels in soybean seeds during natural and accelerated aging. Plant physiology. 1980;66(4):715-719.

30. Michael SD, Taguchi O, Nishizuka Y. Changes in hypophyseal hormones associated with accelerated aging and tumorigenesis of the ovaries in neonatally thymectomized mice. Endocrinology. 1981;108(6):23752380 .

31. Ward KT, Hess M, Wu S. Geriatric assessment in multicultural immigrant populations. Geriatric (Basel). 2019;4(3).

Publisher's Note Springer Nature remains neutral with regard to jurisdictional claims in published maps and institutional affiliations. 